The International Journal of Social Sciences and Humanities Invention 6(08): 5575-5579, 2019

DOI: 10.18535/ijsshi/v6i8.05

ICV 2015: 45.28

ISSN: 2349-2031

(C) 2019, THEIJSSHI

Research Article

\title{
Analysis of Community Social Issues in Jamdin Buyong Editorial Cartoon Press Sabah
} Times

\author{
Suraya Hani Zakaria ${ }^{1}$, Mohammad Pu'ad Bebit, Ph.D ${ }^{2}$, Mohd Sawari Rahim, Ph.D ${ }^{3}$ \\ ${ }^{1}$ Department of Social Science Studies, Institute of Teacher Education, Gaya Campus \\ 88805 Kota Kinabalu, Sabah MALAYSIA \\ ${ }^{2}$ Department of Humanities, Art and Heritage, Universiti of Malaysia Sabah \\ Jalan UMS, 88400 Kota Kinabalu, Sabah MALAYSIA \\ ${ }^{3}$ Department of Social Science Studies, Institute of Teacher Education, Kent Campus \\ Peti Surat 2, 89207 Tuaran, Sabah MALAYSIA
}

\begin{abstract}
This research aims to analyze social issues in more detail in Jamdin Buyong's editorial cartoon work published in the Sabah Times newspaper in 1967. The cartoon produced in the press is an important historical record of civilization. This is because it describes the situation of the community at that time which is the recording of events, life and social society. Social institutions of society are sometimes faced with problems of life and conflict in themselves requires instruction such as reprimand, advice, indirect criticism. Gambling through cartoon can be presented through casual and unpretentious methods. Hence, the strength of this visual arts branch is what painters use to criticize constructively and help solve problems as well as to build harmony and social harmony. However, these visual artworks are not addressed as serious and less attention and references. This study uses a visual semiotic theory approach by Charles Sanders Pierces to explain the meaning that will lead to values as a teaching and guidance. In summary, this study proves that the production of cartoon in representation or symbolic use is used by the painter to make a statement of humorous, sharp or sarcastic criticism. The purpose is to deliver messages, advice and lessons to the community that rely on good positive and moral values to the community. The impact, the content of the values in the cartoons shows the social issues of youth and youth that have begun since the $60 \mathrm{~s}$ to today. Hence, the resulting study is expected to benefit the community and change the meaning and visual concept among the community in order to be a form of documentation for future generation and future reference.
\end{abstract}

Key Words: Cartoons, social issues, semiotic theory and values.

\section{Introduction}

Jamdin Buyong is a figure who contributes a lot to the development of arts, language and culture in Sabah. His talent in writing, research, short story, poem and drama scripts' writing had made him a respectful versatile (Inon Shahruddin, 2006:15) [1]. However, despite his versatility, his great talent in painting is barely known by today's society. Jamdin Buyong's talent in painting was first taught, developed and encouraged by his cousin's brother, Mohd Yaman Ahmad Mus while studying at Government Primary School Built Hill and Sabah College. His talent has been well developed and finally able to shape the painting world in Sabah and brought it to international level. This is proven when he was recognized worldwide and awarded the Certificate of Merit by Clenbrook School Of Art, Australia in 1961 (Inon Shahruddin, 2006:14) [1].

Apart of his great potential in using oil painting, water colour, poster and chalks on canvas or paper within various genres of painting like landscape and abstract painting, Jamdin Buyong also manages to establish his talent in drawing cartoon. His interest was brought to work when he works as a Malaylanguage editor at the Sabah Times in 1963. He authored and started producing sketches in English and Malay language pages. Circa 1964 - 1968, when he was the chief editor of the
Sabah Times press, he is very active in producing editorial cartoons and drawing illustration to embellish the published short stories. For anonymity purposes, Jamdin Buyong uses Jambo as his pseudonym in each of his published editorial cartoon.

\section{Purpose Of Study (Research Problem)}

In contrast with many featured artworks and painting by western and other local painters, the early emergence of cartoon in Sabah has not been taken into account and referred to by researcher and today's society. The development of cartoon in Sabah apparently is not in line with the development of modern art in Malaysia like Muliyadi (2010) [2] who has promoting modern art in Malaysia during the pioneer era to pluralist era of 1930 - 1990. In fact, Sabah's sociopolitical developments in 1960, has actually created new approaches to the production of cartoon which requires further study.

\section{Study Method (Research Method)}

This study is conducted using qualitative method with descriptive historical approach. The selection of this method aims to get a significant and distinctive meaning of concept, sign system, character, symbolism, and symbol and detail definition of something (Borg, 1989) [3]. In this study, 
qualitative approach is used to analyze the content profoundly based on selected classified category which interrelated with each other.

The data are collected from three sources which are primary source, secondary source and oral source (interview). Primary source is the earliest source of information that can be referred to in original form and not yet been defined (Noraini, 2010) [4]. The most important primary source in this study is Jamdin Buyongs' editorial cartoon from 1967's Sabah Times. Secondary source is information collected from newspaper, historical books, journal and dissertation. Oral source (interview) on the other hand, is a medium to really understand the experience and thoughts involved (Patton, 1980) [5]. The data collection method used in this study is document analysis and interview. These methods are considered as the most appropriate methods for the purpose of this study as stated by Cresswell (2005) [6].

\section{Study Analysis}

Semiotic according to Charles Sanders Peirce (1819-1914) is an act, influence or collaboration between three subjects which is sign, object (signifier) and interpretation (signified) as shown in the Triangle Meaning theory. This theory explains the question on how meaning is comprehend from the sign used in the artwork. On the other hand, object is the sign that is referred to using signifiers. On the contrary, interpretation (signified) is something existed in someone's mind about signifier of a sign. When all these three elements interact, interpretation (signified) of an art work will took place.

From Figure 1.1 (i), Peirce's Triangle Meaning is explained. The arrows signify the relation between elements with another. Sign is referred as an image or things, found in the object that been study. Interpretation (signified) is a mental concept issued as sign of experience and knowledge one have about sign and signifier.

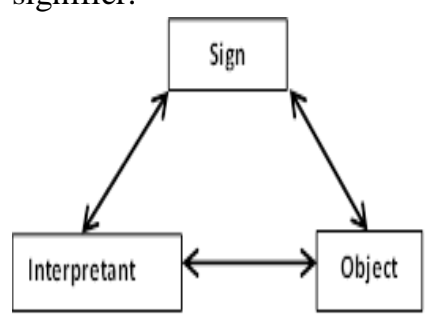

(i)

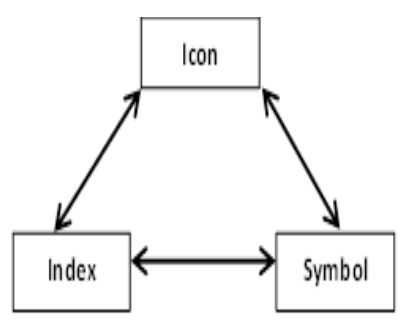

(ii)
Figure 1.1 : Charles Sanders Pierce Triangle Meaning

Peirce also explained that sign always interrelated with their signifiers alike, or having a causal relation with signifier, or because of the existence of conventional relation with the signifier. Based on the object (sign), Peirce divided sign as icon, index and symbol as in Figure 1.1 (ii). Icon is a sign that has a relation between sign, and the signifier has the same nature, physically. In other words, icon is the relation between sign and signifier which looks alike in presenting an artwork. In general, this signifier always can be seen in visual sign such as portraits or maps.

Index is a signifier that shows the existence of holistic nature between sign and signifiers as well as having causal relationship. Besides, it is also one of the signs that directly involved the statement or sign as signifier. For example, the existence of smoke as an index of fire, or a signature as an index of the personality that produces it. Symbol on the other hand shows the nature of sign and signifier that is connecting based on social agreement. For example, the color of white (sign) is as a symbol of purity and cleanliness.

\section{Findings}

Jamdin Buyong comes with social-themed cartoon with its own style and message. This paper was published in the Sabah Times newspaper on January 23, 1967 on page 5 of the National Language column. In contrast to his previous cartoons, he produced cartoons with long dialogue involving several important characters. The initial process is to identify the first to fourth caricature characters as shown in Figure 1.2 below.

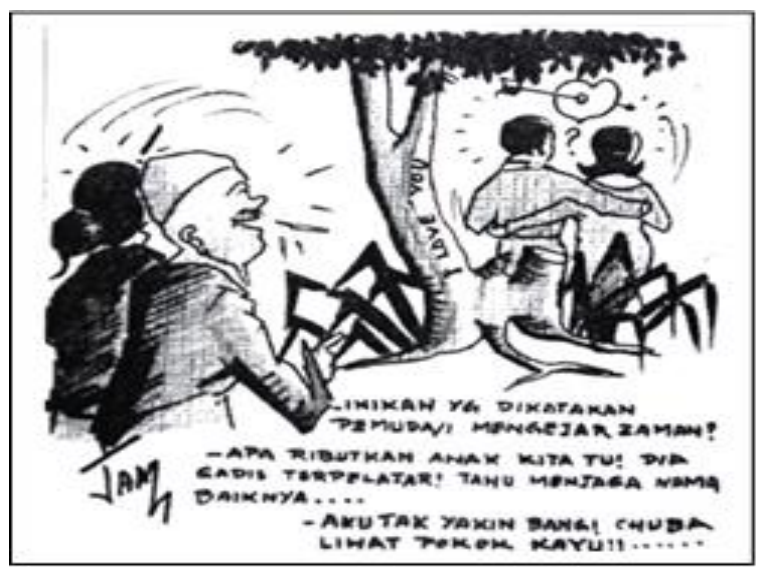

Figure 1.2: Editorial Cartoon Jamdin Buyong in Sabah Times 1967

Source : Sabah Times (1967)

This cartoon uses four cartoon characters. The first male and female characters are married couples of 50-60s of Malays and Muslims, while the second male and female characters are youths and youths in the 20s who are lovers. The researcher uses Charles Sanders Pierce's visual semiotic analysis in directing markers and markers directly related to the cartoon to identify the characters they produce. Hence, the division of icons, indexes and symbols in this cartoon analysis has been shown in Figure 1.5. The purpose is to enable it to connect and formulate the use of the triangle of meaning with interpretation.

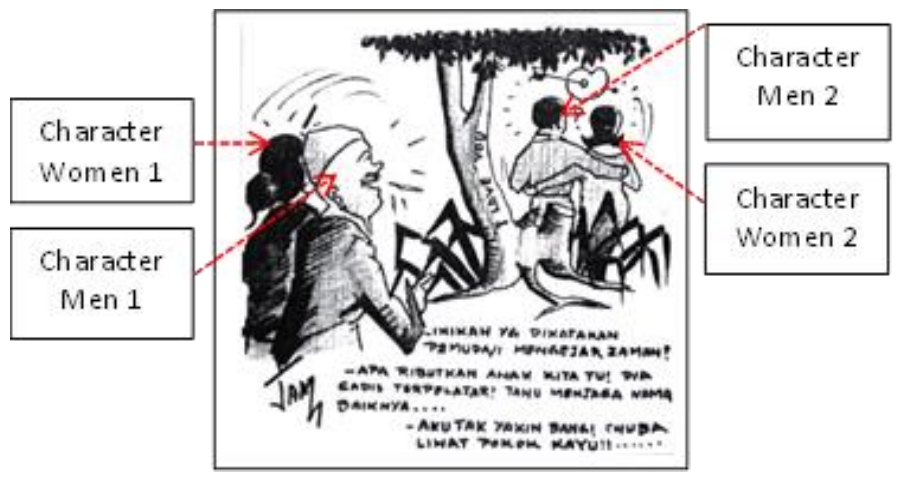

Figure 1.3: The Early Stages of Identifying Cartoon Characters 
An index showing the character of the cartoon is the child of the spouse based on the sign in the dialogue of "our child, the educated girl". This character characterized by Jamdin Buyong wears modern kebaya clothing. Researchers see that there are features that have similarities in Pierce's visual semiotic icon markers through this cartoon character dress with the 'Seniwati Saloma' garment in Figure 1.4. The obvious similarity between the fashion of the shirt and the dress of the cartoon character in this cartoon is that the cuts are similar to the modern kebaya that have a wide neck, body shape, and a fairly tight piece of fabric.

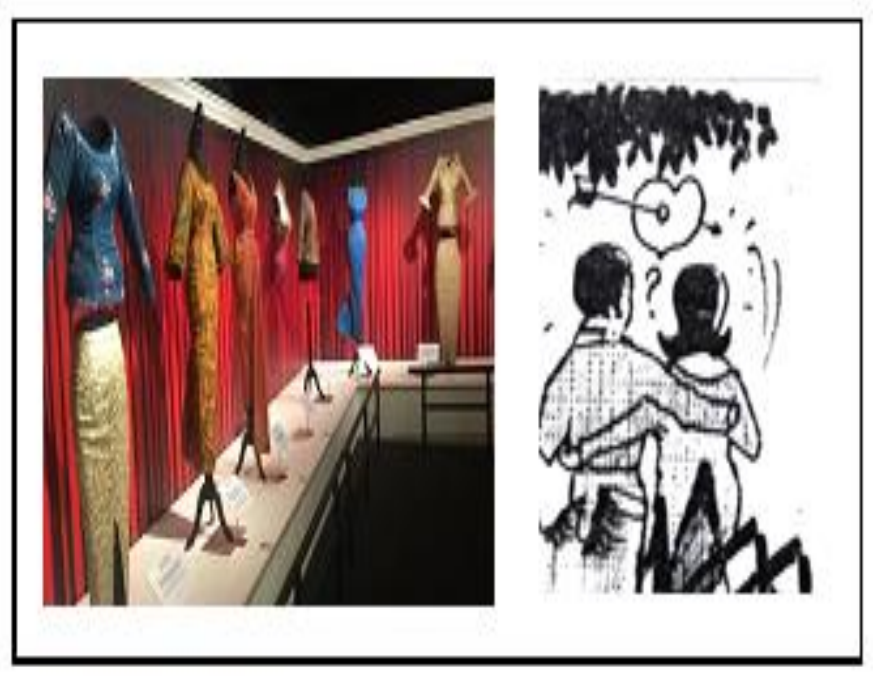

Figure 1.4: Icon Resembling Characteristics

Source : www.berita.media.corp.sg

In addition, there are also signs that aid the analysis process with the index that 'Seniwati Saloma' is regarded as a fashion trendsetter of his day. This art dress is often the craze and craze of other artists and fans. The old man's character as a father is described as having no hair, wearing a long coat and shirt as a traditional Malay shirt as an index referring to the male muslim dress (Aman, 2012:41) [7]. While the character of his longhaired wife is buned. Both of these cartoons are described as having medium sized bodies. His mother's body and clothing were concealed, only a dark color that showed a woman with her hair embraced as a sign in the cartoon. This is an index that the wives are the second subject that supports her husband's character as the first subject in the cartoon produced. The face expression of the mother character is invisible as it is drawn from the back, while the character of the father is drawn on the side view and is in dialogue with his wife. They both looked at the young couple who were under the tree.

The father's character seems to show a lifting style while talking to his wife while watching the young couple and the young man. All these signs indicate that the focus or issue of a conversation between a spouse is to refer to a young man. At the same time become an index of the analysis that is run. His wife's dialogue questioned "Is This the Youth Pursuit of the Youth" ?, welcomed her husband's words "What a Boy We Feared! "She's a Learned Girl!”. "Know to Keep the Dignity .... ". Then his wife replied again by saying "I'm Not Sure!". "Try to See Wooden Trees !! ...... All the dialogs in this cartoon are signs that carry markers to break the essence of the cartoon produced by Jamdin Buyong. The last dialogue of the wife who told her husband's caricature's character to look at the tree was to the "I Love U" in the middle of a large tree. His writings are produced vertically, drawn from the bottom to the tree trunk that depicts a couple of lovers to express their love. The word "I Love U" is an abbreviation for "I Love You" taken from English, meaning "I Love You". This sign refers to the index that love is a very sensual feeling or passion (between love, affection) between man and woman.

Basically, love means things that give a sense of belonging like laughing, working and respecting each other. Love is divided into three main components. First is to be concerned and sensitive to partner satisfaction. Secondly, the integrity of a bond or the desire to always be first and foremost is the confidentiality of intimacy in communicating intimacy. These three components are integrated will give birth to a feeling known as love (Mohd Makzan, 1997) [8].

The beloved couple who are meant to be in love are portrayed through the caricature of youth and girls. The caricature character of youth and girls walks while hugging each other's waist as an index of familiar relationships. There is a use of heart-shaped symbols on the head of the couple to reinforce the mark they are in love. The use of heart illustrations as a symbol of love has expanded in Europe in the 15th century (Akhmad Muawal, 2018) [9], depicted in red as a symbol of blood, passion and emotional power often associated as a symbol of love.

This heart-shaped symbol is also derived from a kind of "silfium" plant originating in North Africa used as a contraceptive drug. The use of contraceptives with the symbols of love used in America and Europe means free sex without obligation (Hokky, 2016:22) [10]. This heart-shaped symbol has reached Asian countries through trade routes around the 1550s (Akhmad Muawal, 2018) [9]. The relationship between sex between men and women without the need to assume responsibility is an index of free association. This western culture has absorbed into the life of the people who set aside morals, customs and religion (secular culture). This sign is in line with the law that free association between males and females is absolutely prohibited in Islam and this phenomenon will lead to the collapse of moral values and thus tarnish the purity of pure Islam. The free association between the youth and the youth is supported by Muhtadi (2007:258) [11] as one of the major problems that spread in society. This free association will bring a variety of problems, including free sex and cohabitation that have side effects such as childbirth, baby dumping and so on (Ho, 2003:192) [12]. The value marks that address this issue in relation to this law are the values of da'wah.

The position of youth and youth pairing behind the parent's character has actually been a sign of visual semiotic theory. This sign goes with the index. the act of juvenile youth is done in secret without the knowledge of both parents. The location of these scenes takes place in a park or a lonely environment from the crowd with a sign of a grafted plant roughly drawn in thick and dark colored lines. Likewise, the roots of the trees appear to be strong and strongly painted with considerable 
shape while the leaves of the trees look half-height reflecting the beauty and silence of the place without interruption. The inclination of the beloved young man to love and to love in these distant places will bring them closer to their desires. Humans who act according to lust will easily get caught up in the vicious world. Al Ghazali (1997), Jaafar (1996) and Ibn Jauzi (2000) in Muhtadi (2007) [11] explain that every human being has the lust. Lusts act according to the heart. The creation of God S.W.T called the devil often encourages humans to fulfill their demands in a fairly subtle way. Satan demonstrates the beauty and goodness of his despicable nature. At this stage humans can feel like those who are on the right path and get directions, but the devil has deceived in the way of deceiving without human being.

Humans who act according to lust will also lower their dignity. If the impulse of sexual desire is to defeat the intellect, it can lead to the sins (Abu Fahmi, 1990) [13]. Although the passion does not enjoin the sin, it remains an obstacle to seeking happiness - knowledge and charity. This is because lust sometimes causes lustful love ('isyq), and those who give up on lustful love are perceived by al-Ghazali, for not knowing the purpose of sexual desire so they fail to control the passions beyond the abject animal (Abu Fahmi, 1990) [13]. The romance of the youths is also often the cause of their increasingly disturbing social harms such as out-of-marriage pregnancy, infectious diseases and so forth (KH.Husein, 2001:132) [14]. The sign in the article "Is This the Youth Pursuit of Youth?" To be an index to the question of the direction of youth in modern times. This verse questioned the truth of the behavior of this young man's spouse with the advancement and change of the age. The 'chase times' dialogue is an index for progress. Then it should be, the young men who behave in parallel and in accordance with the demands of the state's progress.

The wording of the young men in the pursuit of this era was once directed by Abdul Rahim (2006:89) [15] states that the excitement of pursuing national progress can lead to devastation from the spiritual point of view, such as the free association among young people who need the firm commitment and attention of the parents (Abdul Rahim, 2006:89) [15]. There is a contradiction to the question of the character of the mother as well as bringing a mark of dissatisfaction with her heart to see what is happening. There is a sign of the problem in her husband's dialogue, "What's Wrong With Our Child! She's a Learned Girl! Know to Keep the Dignity .... ". Jamdin Buyong puts a deep sarcasm in this dialogue through a link between a learned girl who knows to keep a good name with the behavior of the girl's caricature character. The real reality illustrated in the cartoon is a girl who spoils the good name and family with the wrong behavior of religious and cultural points.

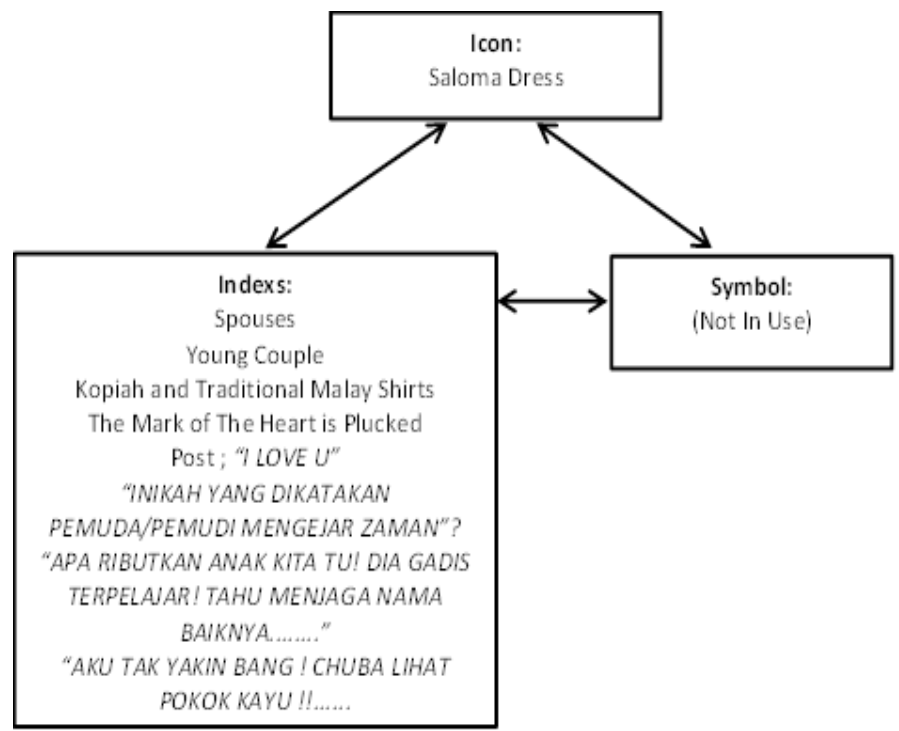

Figure 1.5: Distribution of Icon, Indexs and Symbols

The causal relationship in the "learned girl" mark with a "know-how keeper" marker also brings an overview of the concept of knowledge in forming one's personality and personality. Hamka states that a student should endeavor to make himself behave in harmony with his level of knowledge, but the Quran criticizes the knowledgeable person, but does not implement it (Abd Haris, 2010:166) [16]. This conclusion leads to the marker of da'wah values in this cartoon.

According to the Islamic perspective, the knowledge gained by one person will not bring meaning and meaning if it fails to form a morality that is in line with the paradigm of Islam itself (Ahmad Sunawari, 2015:172) [17]. This situation shows that there is a clue in the filling of knowledge learned by the girl's character, the effect of secularism in education. While Ishak (2006:122) [18], explains the arrival of Western orientalists bringing elements of secularism that affects the minds of the local community.

Secularism is a religion that begins in Europe to separate religion from world affairs (Syed Muhammad Al-Naquib, 1978:13) [19]. This understanding is used by western orientalists around the world to undermine the morality of Muslims. The inclusion of secularism in Malaysia begins with the understanding of the modernity brought about by British colonialism by spreading it directly or indirectly within the local socio-cultural space (Safrizal, 2012:235) [20].

This western ideology and ideology also enters into the culture of Malaysian society as a way to exploit the culture of other communities in the interests of their own influence and power. In fact, new social developments in Malaysia have been designed by the west with the migration of foreigners bringing conflict and value conflicts in the local culture (Aziz, 1975:106) [21].

As Sulaiman Esa (2012:253) [22] explains that society experiences social alienation and is easily affected by humanistic, materialistic and secular western ethics and values that conflict with religious values and norms of life. Those who call on the mixing of women with men in the Islamic state, and those who want this attitude to spread across our social lives, they are, in fact, none other than propaganda tools, and 
implementers of Islamic enemy lines of ideology glorifying materiality, mischief and misunderstandings (Abdullah Nasih, 1988: 339) [23].

In this regard, parents have a great responsibility to educate children from small to adult. Islamic law claims that parents are paying close attention to their children carefully, especially during the period of tamyiz and adulthood (Abdullah Nasih, 1988) [23]. Among the important things that parents need to examine include who they are mingling, where they go and what they do (Abdullah Nasih, 1988) [23].

In addition, the entertainment factor is also part of the youths who are stuck in this world of love. The rapid development in the field of entertainment either in terms of print media and electronic media has a lot to do with it. In the same way, entertainment in the form of print media such as magazines and newspapers has reported many western cultures that have had sex trends at a young age to poison the youth's thinking and result in their involvement. Western cultures often spread the negative things that are contrary to Islamic values.

Young people are not encouraged to be involved in romance even though they sometimes bring some benefits. But the undesirable harm it brings is more. Therefore, the reasonable demands of kosher sex are free from all disobedience. It does not fail to fulfill God's intention to instill sexual impulses in humans, nor is it a hindrance to the main advice towards happiness (Abu Fahmi, 1990) [13].

Accordingly, the integrity and firmness of the family system are also very important for the well-being of society in a country. A society will lose its strength if its members do not perform their obligations to the family. On the contrary, happiness and prosperity will be achieved when everyone behaves appropriately as a family member. This means everyone has to carry out their duties to their families. Some researchers who highlight the history will assume that the collapse of some of the major civilizations such as Roman civilization is due to the split of the family system (Ismail, 2001:97) [24].

\section{Conclusion}

Jamdin Buyong is the one who contributes his advice and opinions through his creative and artistic works of art (Inon Shahruddin, 2006:1) [1]. This is because his editorial cartoon has a keen assertion to the community at that time. However, he uses his own style and style by incorporating humor or joke elements that can attract readers.

This study proves that these visual cartoon materials are not just a hobby or complete empty space in the newspaper for viewing and being kept as a viewing material only. Editorials cartoons can be used as valuable historical documentaries as every cartoons are able to peer out issues of society at a time.

This kind of artwork is produced on the basis of the manifestations of the ideas and ideas of his painters to highlight his or her stand, life or philosophy of life. True painting creates and reflects the spirit and individuality of the people who develop a nation (Safrizal, 2012) [20]. In this regard, editorial cartoons published in Sabah's local newspapers play an important role in highlighting social issues of society to educate press readers to be more sensitive to the sensitivities of the local community. Indirectly, the impact of this cartoon painting shows the contribution to the development of the community in Sabah to make the value of the nation's most valuable civilization.

The young generation and academic experts are expected to be able to examine and appreciate the art materials as reference material and guidance in delivering detailed meanings and interpretations of the images and subjects used.

\section{References}

1. Datuk Jamdin Buyong Language and Literature Fighters Inon Shahruddin Abdul Rahman. .2006.

2. Malay Editorial Since 1990 Muliyadi Mahamood. . 2010.

3. Educational Research (5th ed). Borg, W. R., \& Gall, M. D. .1989.

4. Research In Education Noraini Idris. 2010.

5. Qualitative Evaluation and Research Methods (2nd ed.) Patton, M. Q. .1990.

6. Educational Research Planning, Conducting, and Evaluating, Quantitative and Qualitative Research (2nd ed) Cresswell, J. W. .2005.

7. Comparison of Dastar Application In Sikhism With Islam In Islam Aman Daima. .2012.

8. Homosexuality: The current family challenges, Family institutions face new millennium challenges Mohd Makzan Musa. .1997.

9. Humanities Akhmad Muawal Hasan. .2018.

10. Nusantara Codes Hokky Sutingkir. .2016.

11. Bring Your Family To Heaven Muhtadi Kadi. .2007.

12. Romance Among Teenagers Ho Fuei Tien. .2003.

13. Ethics Beramar Ma'ruf Nahi Mungkar Ibu Taimiyyah Abu Fahmi. .1990.

14. Fiqh Female Reflection of Kiai On Religious Discourse and Gender KH.Husein Muhammad. .2001.

15. Family Institutions Facing The New Millenium Challenge Abd. Rahim Abd. Rashid. .2006.

16. Ethics Hamka Abd Haris. .2010.

17. Ibn Khaldun's Philosophy Ahmad Sunawari Long. .2015.

18. History of Malay Socio-Culture Ishak Bin Saad. .2006.

19. Islam and Secularisme Syed Muhammad Al-Naquib AlAttas. .1978.

20. Islam and Modern Art in Malaysia Safrizal Shahir. .2012.

21. Society and Culture of Malaysia Aziz Deraman. .1975.

22. Islamic Identity in Fine Arts: Search and Challenges Sulaiman Esa. .2012.

23. Education of Children In Islam Volume 1 Abdullah Nasih Ulwan. .1988.

24. Introduction To Sosial Science Ismail Yusoff. .2001. 